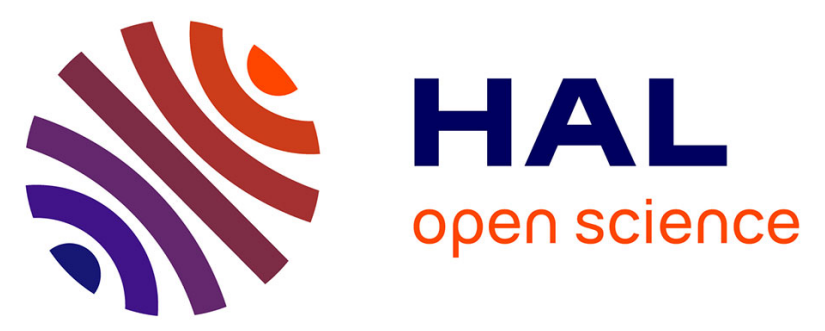

\title{
Chapter 9. Molecular Structure and Dynamics of Nano-Confined Water: Computer Simulations of Aqueous Species in Clay, Cement, and Polymer
} Membranes

\author{
Andrey G. Kalinichev
}

\section{To cite this version:}

Andrey G. Kalinichev. Chapter 9. Molecular Structure and Dynamics of Nano-Confined Water: Computer Simulations of Aqueous Species in Clay, Cement, and Polymer Membranes. Lionel Mercury; Niels Tas; Michael Zilberbrand. NATO Science for Peace and Security Series C: Environmental Security. Transport and Reactivity of Solutions in Confined Hydrosystems., pp.99-111, 2014, Transport and Reactivity of Solutions in Confined Hydrosystems., 978-94-007-7533-6. 10.1007/978-94-007-75343_9. in2p3-01577629

\section{HAL Id: in2p3-01577629 \\ https://hal.in2p3.fr/in2p3-01577629}

Submitted on 9 Oct 2018

HAL is a multi-disciplinary open access archive for the deposit and dissemination of scientific research documents, whether they are published or not. The documents may come from teaching and research institutions in France or abroad, or from public or private research centers.
L'archive ouverte pluridisciplinaire HAL, est destinée au dépôt et à la diffusion de documents scientifiques de niveau recherche, publiés ou non, émanant des établissements d'enseignement et de recherche français ou étrangers, des laboratoires publics ou privés. 


\section{COMPUTER SIMULATIONS OF AQUEOUS SPECIES IN CLAY, CEMENT, AND POLYMER MEMBRANES}

Andrey G. Kalinichev ${ }^{1,2}$

${ }^{1}$ Laboratoire Subatech, UMR 6457, Ecole des Mines de Nantes, 44307 Nantes, FRANCE

2 Department of Chemistry, Michigan State University, East Lansing, MI 48824, USA

Abstract. Molecular-level knowledge of the thermodynamic, structural, and transport properties of water confined by interfaces and nanopores of various materials is crucial for quantitative understanding and prediction of many natural and technological processes, including carbon sequestration, water desalination, nuclear waste storage, cement chemistry, fuel cell technology, etc. Computational molecular modeling is capable to significantly complement the experimental investigations of such systems by providing invaluable atomic-scale information leading to improved understanding of the specific effects of the substrate structure and composition on the structure, dynamics and reactivity of interfacial and nano-confined aqueous solutions. This paper offers a brief overview of recent efforts to quantify some of these effects for individual $\mathrm{H}_{2} \mathrm{O}$ molecules and hydrated ions confined at the interfaces and in nanopores of several typical hydrophilic and hydrophobic materials. The first molecular layer of aqueous solution at all substrates is often highly ordered, indicating reduced translational and orientational mobility of the $\mathrm{H}_{2} \mathrm{O}$ molecules. This ordering cannot be simply described as "ice-like", but rather resembles the behavior of supercooled water or amorphous ice, although with very significant substrate-specific variations.

\section{INTRODUCTION}

Most chemical reactions near the Earth's surface involve fluid (aqueous) phases and take place at fluid-solid interfaces or in confined spaces of mineral interlayers and nanopores. These reactions affect many important natural processes, including mineral weathering, adsorption or release of environmental contaminants in soil, drinking water quality, formation and behavior of ice nano-crystals and hydrated mineral nano-particles in the atmosphere, the fate of $\mathrm{CO}_{2}$ in geologic carbon sequestration. The same interfacial phenomena are also at the core of many important technological processes related to water purification and desalination mambranes, fuel cells, production and utilization of cement, etc. All these phenomena are inherently multi-scale in time and space, and addressing the scientific and technological problems they pose is multidisciplinary. Molecular-level knowledge of the chemistry and physics of interfacial and confined aqueous solutions interacting with mineral surfaces and other substrates is essential to their understanding. Important questions center on how water and dissolved species behave at the surfaces and in nanoconfinement by different inorganic and organic substrates.

Current understanding of hydrated mineral-water interfaces is far from complete. Molecular-scale information is difficult to obtain experimentally due to the nature of the materials (e.g., interfacial and bulk structural disorder, the presence of molecular scale dynamical disorder with characteristic time scales that span many orders of magnitude, the physical limitations on the samples that can be effectively examined, and the difficulty of experiments under extreme conditions). Mineral surfaces themselves vary by the arrangements and reactivity of individual surface functional groups and the specific adsorption of inorganic and organic ions. Even the utility of macroscopic thermodynamic concepts, such as the dielectric constant and electric double-layer, remain open and are important questions driving the current research [1-3]. Modern experimental probes, including synchrotron light sources, high-resolution neutron scattering, time-resolved spectroscopy and diffraction, scanning force microscopy, and multi-dimensional NMR spectroscopy, are providing unprecedented, atomic-level and surface-specific information about mineral-fluid systems [3-5]. However, it is often difficult to interpret these experimental observations without parallel theoretical and computational studies [6-7]. In addition, the interaction with experimentalists is imperative for verifying theoretical models and guiding larger scale simulation efforts. Connecting computational and experimental results is crucial in addressing these questions and in bridging the gap between the atomic- and nanometer-scales and the micron- and larger scales that is essential for environmental, geochemical and energy applications of practical importance [8].

The methods of atomistic computer simulations [9], often coupled to surface-specific experimental results, are already mature enough to provide otherwise unobtainable perspective into the structure, dynamics and energetics of fluid-mineral systems [10]. Computational approaches range from traditional quantum chemical methods to classical molecular dynamics (MD) and Monte Carlo (MC) simulations using semi-empirical interaction potentials to emerging methods including quantum molecular dynamics, metadynamics, and reactive force fields for molecular-scale modeling [11-35]. Critical questions currently revolve around the effect of solid surfaces on the properties of near-surface and 
nano-confined fluids, structural and chemical modification of the surface by the fluid, the pathways of chemical reactions at surfaces and in fluids, the connections between these reactions and fluid structure and dynamics, and the consequent effects on the pathways of dissolution and precipitation. This paper provided a brief overview of our group's recent efforts to quantify some of these properties and processes at the interfaces and in nano-confinement with several typical hydrophilic and hydrophobic materials by classical MD simulations using the CLAYFF force field [12].

\section{COMPUTATIONAL MODELS AND METHODS}

We compare the molecular structure of several qualitatively different substrate-water interfaces. Crystals of metal hydroxides, line brucite, $\mathbf{M g}(\mathbf{O H})_{2}$, or portlandite, $\mathbf{C a}(\mathbf{O H})_{2}$, can be naturally cleaved parallel to their (001) crystallographic plane, resulting in an electrostatically neutral surface fully covered by OH groups oriented away from the surface. They can easily form hydrogen bonds with interfacial $\mathrm{H}_{2} \mathrm{O}$ molecules. Therefore, we will use the surface of portlandite as a reference model of a hydrophilic interface [11,20]. A similar hydrophilic surface can be created by cleaving the crystal structure of quartz, $\mathrm{SiO}_{2}$, parallel to the (001) plane. In the presence of water and at relatively low $\mathrm{pH}$, this surface will also be fully covered by $\mathrm{OH}$ groups [36]. In the structure of hydrocalumite, $\left.\mathbf{C a} 2 \mathrm{Al}(\mathrm{OH})_{6}\right] \mathbf{C l} \cdot 2 \mathrm{H}_{2} \mathrm{O}, 1 / 3$ of the divalent $\mathrm{Ca}$ cations are isomorphically substituted by trivalent $\mathrm{Al}$, resulting in a positive structural charge compensated by the presence of $\mathrm{Cl}^{-}$or some other anions in the interlayer space and on the surfaces of this material, an anionic clay [11,20]. Similar to its neutral portlandite analog, its cleaved (001) surface is also fully covered by $\mathrm{OH}$ groups and can be considered hydrophilic.

The structure of talc, $\mathbf{M g}_{3} \mathbf{S i}_{4} \mathbf{O}_{\mathbf{1 0}}(\mathbf{O H})_{2}$, consists of so-called TOT layer (an octahedral layer of $\left[\mathrm{MgO}_{4}(\mathrm{OH})_{2}\right]$ sandwiched between two tetrahedral layers of [ $\left.\mathrm{SiO}_{4}\right]$ ) stacked along the crystallographic $Z$ direction [18,21,27]. All tetrahedral sites are occupied by $\mathrm{Si}$ forming $\left[\mathrm{SiO}_{4}\right]$ structural units, and all octahedral sites are occupied by $\mathrm{Mg}$ forming $\left[\mathrm{MgO}_{4}(\mathrm{OH})_{2}\right]$ units. The TOT layers are, thus, electrostatically neutral and interact with each other only by weak by van der Waals forces, reflecting the hydrophobic nature of the basal siloxane Si-O-Si (001) surface. The TOT layered structure is typical for many clay minerals, which can develop various degrees of negative structural charge due to the isomorphic substitutions possible for both tetrahedral (e.g., Al for $\mathrm{Si}$ ) and octahedral (e.g., Li for Mg) layers. The emergence of negative layer charge is balanced by the presence of charge-balancing cations in the interlayer space and on the surfaces of these minerals and makes them more hydrophilic. Their interaction with water have already been extensively investigated [12,25,26,29,30,32,37] and we focus here only on the behavior of neutral talc, as a reference hydrophobic surface.

It is known experimentally (e.g., [38]) that mineral surfaces rarely exist in nature in the atomically smooth ideal form as the ones listed above. To illustrate the effects of nanoscale surface roughness of the substrate on the structural and dynamic properties of the interfacial aqueous solution, the surface of tobermorite, $\mathbf{C a}_{5} \operatorname{Si}_{6} \mathbf{O}_{16}(\mathbf{O H})_{2}$, is taken here for comparison. Tobermorite is also known as one of the so-called C-S-H (calcium silicate hydrate) phases in cement chemistry and its surface properties control behavior of confined water in the nanopores of cement and concrete $[11,20]$.

The disordered interfaces of water filtration membranes are also typically characterized by the surface roughness on the nanoscale and above. In this case, the diversity of the surface adsorption sites can be very large and it is not always possible to identify and investigate all of them individually of a truly atomistic level. Nevertheless, computer simulations can still provide invaluable information about the molecular mechanisms of the processes of membrane filtration. The effects of various metal cations and their interactions with dissolved natural organic matter on the process of bio-fouling of polyethersulfone (PES) desalination membrane is taken here to illustrate the case [39].

All MD simulations described here were performed at ambient conditions in the $N V T$ statistical ensemble (constant number of atoms, constant volume, and temperature $T=300 \mathrm{~K}$ ) after a pre-equilibration in the $N P T$ ensemble at $T=300 \mathrm{~K}$ and $P=0.1 \mathrm{MPa}$ using standard MD algorithms [9]. The mineral surfaces were constructed by cleaving the bulk crystal structures parallel to the (001) plane. The irregular polymer surface was created in the course of preliminary MD runs of condensing a polyethersulfone polymer chain consisting of 60 monomer units [39]. Each complete interfacial MD simulation cell consisted of a substrate slab about 2 to $3 \mathrm{~nm}$ thick, and a layer of liquid water about 3 to $7 \mathrm{~nm}$ thick placed in contact with them, as illustrated in Fig.1. The water was pre-equilibrated at $300 \mathrm{~K}$ and 0.1 MPa. Periodic boundary conditions [9] were then applied in all three dimensions to produce models of the interfaces formed by infinite (in $x$ - and $y$ directions) flat substrate layers interspersed with layers of water. In all cases, the thickness of the water layer and the size of the cell in the $z$-direction (normal to the surface) were sufficiently large to effectively exclude direct interactions between two different substrate/water interfaces created due to the periodicity of the system. The number of $\mathrm{H}_{2} \mathrm{O}$ molecules in the layer was chosen to reproduce the density of bulk water under ambient conditions $\left(\sim 1 \mathrm{~g} / \mathrm{cm}^{3}\right)$. The final $x$-, $y$-, and $z$-dimensions of the simulation supercells were approximately $2 \mathrm{~nm} \times 2.5 \mathrm{~nm} \times 10 \mathrm{~nm}$ with slight variations depending on the nature of the substrate. 


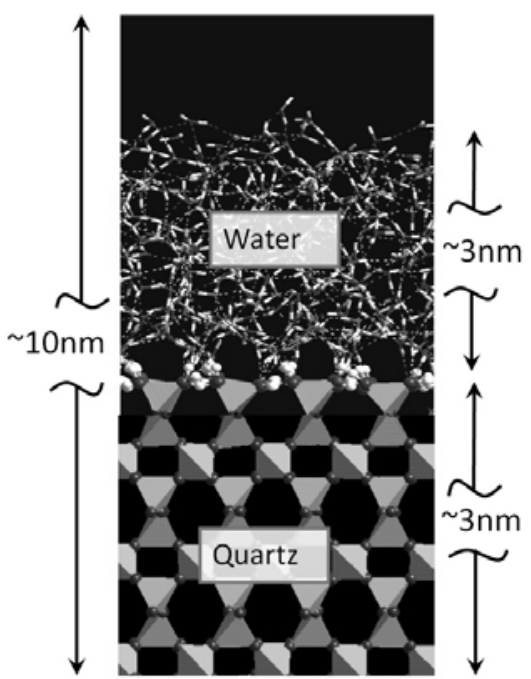

Figure 1: A schematic view of the molecular dynamics periodic simulation cell for the modeling of a substrate-water interface. Bulk quartz $\mathrm{SiO}_{2}$ crystal is shown as tetrahedral ( $\mathrm{Si}$ ) and dark balls (O). White $(\mathrm{H})$ and dark $(\mathrm{O})$ balls represent the O-H groups of the fully hydroxylated surface. Approximately half of the surface $\mathrm{O}-\mathrm{H}$ groups are bent to make hydrogen bonds among themselves, while the other half - donate H-bonds to the interfacial $\mathrm{H}_{2} \mathrm{O}$ molecules, which are shown as white $(\mathrm{H})$ and dark (O) cylinders above the surface. H-bonds are indicated as thin dashed lines.

The MD time step was $1.0 \mathrm{fs}$, and each model system was allowed to equilibrate for at least 500 ps of MD before an equilibrium MD trajectory for each model was accumulated at 10 fs intervals during additional 500 to 1000 ps of MD simulation. The details of the MD simulation procedures and parameter settings for mineral-water systems are described in previous publications [11,12,18,20,27,37,39-41]. The structural analysis of the near-surface water films was undertaken using atomic density profiles in the direction perpendicular to the substrate surface and atomic density maps within defined slices of the water film parallel to the surface. These properties were all calculated by averaging over the last 500 ps equilibrium MD trajectory of each system. The position of the mineral surface $(z=0)$ was defined by the average position of the top-most surface oxygen atoms or of the corresponding $\mathrm{OH}$ groups, depending on the substrate.

\section{SIMULATED RESULTS AND DISCUSSION}

\subsection{Interfacial water structure}

Fig. 2 shows the time-averaged atomic density contour map of $\mathrm{O}_{\mathrm{w}}$ in the first molecular layer of water on the (001) surface of quartz. It is important to note, that unlike the surfaces of brucite [18] and portlandite [11], only about $50 \%$ of the surface hydroxyl groups on quartz are oriented away from the surface and easily donate $\mathrm{H}$-bonds to the interfacial $\mathrm{H}_{2} \mathrm{O}$ molecules. The other $50 \%$ of the surface $\mathrm{OH}$ groups are oriented parallel to the surface of quartz, form $\mathrm{H}$-bonds to other surface hydroxyls, and accept $\mathrm{H}$-bonds from $\mathrm{H}_{2} \mathrm{O}$ molecules (Figs1,2). The surface ordering of the $\mathrm{H}_{2} \mathrm{O}$ molecules is clearly observed in the time-averaged patterns of the $\mathrm{O}_{\mathrm{w}}$ distribution. Surface water molecules are significantly immobilized by each accepting an $\mathrm{H}$-bond from one surface $\mathrm{OH}$ group and simultaneously donating one H-bond to another neighboring surface $\mathrm{OH}$ group. A similar pattern of $\mathrm{H}_{2} \mathrm{O}$ ordering is also observed at the neutral hydroxylated surfaces of brucite [18] and portlandite [11]. However, the charged hydroxylated surface of hydrocalumite exhibits a completely different behavior where no H-bonds donation is possible for the interfacial water molecules [11].

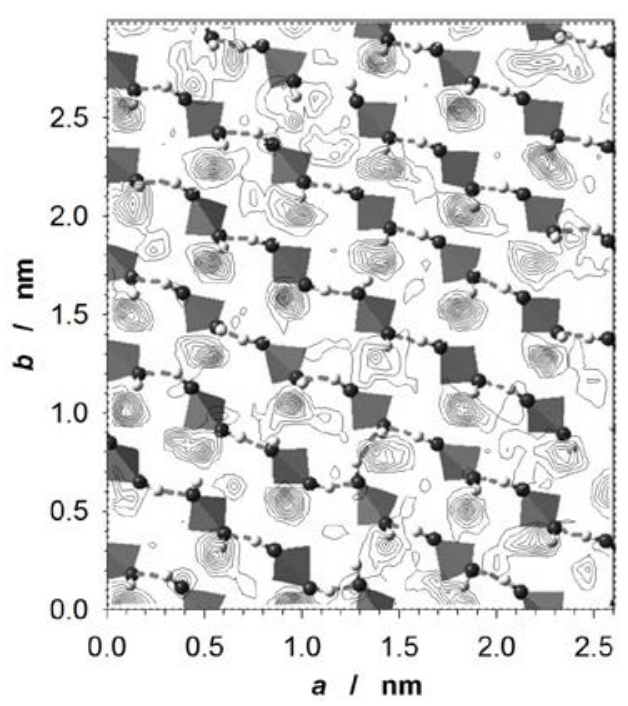

Figure 2: Contour maps of the atomic density of oxygens of $\mathrm{H}_{2} \mathrm{O}\left(\mathrm{O}_{\mathrm{w}}\right)$ within the first molecular layer of water at the fully hydroxylated (001) surface of quartz, which is shown below the contours as tetrahedra $(\mathrm{Si})$ and dark $(\mathrm{O})$ and white $(\mathrm{H})$ balls . See Fig. 1for the detailed notations. 
This is clearly visible from the comparison of the atomic density profiles for $\mathrm{O}_{w}$ and $\mathrm{H}_{\mathrm{w}}$ of these surfaces, which provide important additional insight into the ordering of water molecules at the interface. Two orientations of $\mathrm{H}_{2} \mathrm{O}$ molecules are energetically most favorable for the formation of stable hydrogen bonds to the hydroxylated surfaces of portlandite and quartz (Fig.3a,b). In one of them, water molecules have one H-atom directed toward an O-atom of the surface hydroxyl, thus donating an H-bond to the surface. This is reflected in the presence of a strong peak at $\sim 0.2 \mathrm{~nm}$ on the $\mathrm{H}_{\mathrm{w}}$ density profiles. In this orientation, the second $\mathrm{H}$-atom contributes to the peak at $\sim 0.35 \mathrm{~nm}$. However, a stronger contribution to the $0.35 \mathrm{~nm}$ peak in the $\mathrm{H}_{w}$ distribution arises from the other favorable $\mathrm{H}_{2} \mathrm{O}$ orientation, in which it accepts an $\mathrm{H}$-bond donated by the surface hydroxyl groups. In this case, both $\mathrm{H}_{\mathrm{H} 2 \mathrm{O}}$ of the surface water molecule contribute to the density profile peak at $0.35 \mathrm{~nm}$. In both preferred orientations of the surface water molecules, their O-atoms are located approximately at the same distance from the surface $(\sim 0.25-0.28 \mathrm{~nm})$. The ability of the surface water molecules to both donate and accept H-bonds to the substrate surface creates a very well developed $\mathrm{H}$ bonding network across the interface with the structure strongly resembling that of bulk liquid water. O-O and O-H radial distribution functions of liquid water are shown as thick dashed lines in Fig. 3 to illustrate this similarity. The $g_{\mathrm{OH}}(r)$. peak at $\sim 0.2 \mathrm{~nm}$ is a definitive signature of donated hydrogen bonds in the system, while the $g_{\mathrm{OO}}(r)$ peak at $\sim 0.45 \mathrm{~nm}$ clearly indicates that the local ordering of the H-bonding network is close to tetrahedral - a typical characteristic of bulk liquid water structure.
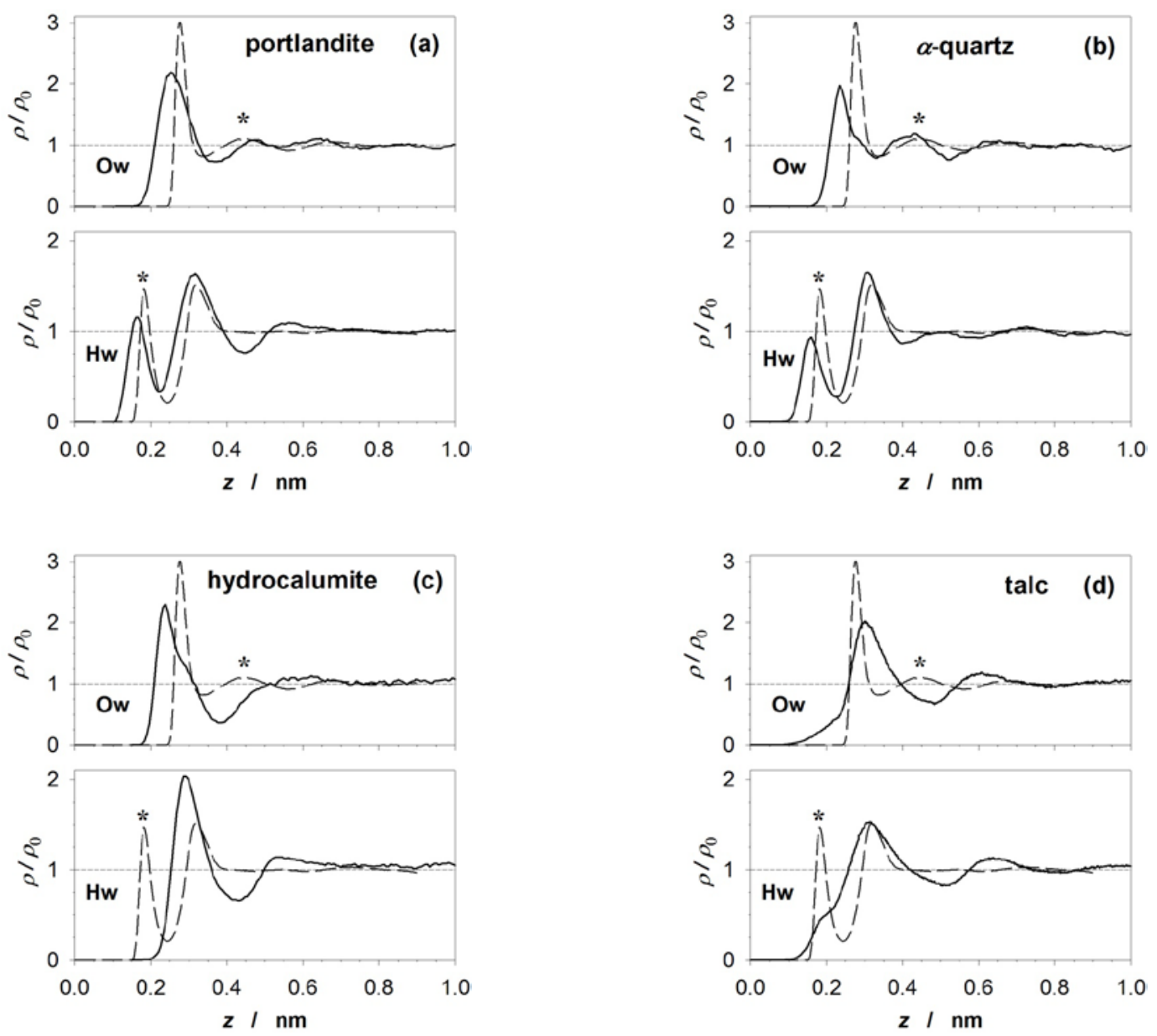

Figure 3: Density profiles of $\mathrm{O}_{\mathrm{w}}$ and $\mathrm{H}_{\mathrm{w}}$ atoms of the interfacial $\mathrm{H}_{2} \mathrm{O}$ molecules as functions of the distance from the surface $(z)$ of four different mineral substrates. Origin of $z$ is defined here for all surfaces as the average $Z$-coordinate of the oxygen atoms at the substrate surface. The local density $(\rho)$ is normalized with respect to the corresponding atomic density in bulk liquid water $\left(\rho_{0}\right)$ and the radial distribution functions $g_{\mathrm{OO}}(r)$ and $g_{\mathrm{OH}}(r)$ of bulk liquid water are shown as thick dashed likes for comparison. Stars mark the characteristic H-bonding features of these functions.

For hydrocalumite (Fig.3c) the computed near-surface water structure is strikingly different. Due to the positive structural charge of this substrate, the $\mathrm{H}$-bond donation to the surface by $\mathrm{H}_{2} \mathrm{O}$ molecules is prevented and the 
well-interconnected H-bonding network is not formed in the interfacial region [11], despite the fact that the $\mathrm{H}_{2} \mathrm{O}$ molecules are strongly attracted to this surface and it is clearly hydrophilic.

The atomic density profiles of the surface water on talc (Fig.3d) show that $\mathrm{H}_{2} \mathrm{O}$ molecules are located somewhat farther away than from the previously discussed hydrophilic surfaces (Figs.3a-c) and the $\mathrm{H}_{2} \mathrm{O}$ molecular orientation is predominately parallel to the surface (the peaks of $\mathrm{O}_{\mathrm{w}}$ and $\mathrm{H}_{\mathrm{w}}$ are approximately at the same distance of 0.3-0.32 nm), in accordance with the hydrophobic character of talc. However, donation of weak H-bonds is still possible to this surface, as is clearly evident from the shoulders of the $\mathrm{O}_{\mathrm{w}}$ and $\mathrm{H}_{\mathrm{w}}$ distributions around $0.2 \mathrm{~nm}$. Thus, talc surface exhibits a weak degree of hydrophilicity under ambient conditions, which can be most pronounced at very low relative humidity [33], or can even be turned into a strongly hydrophilic surface by the application of very high pressures and temperatures typical for the Earth's mantle conditions [40,41].

\subsection{Interfacial water dynamics}

The simulated diffusional dynamics of surface water is in agreement with these observations: the $\mathrm{H}_{2} \mathrm{O}$ molecules have noticeably higher mobility at the hydrophobic surface of talc and significantly lower mobility at all hydrophilic surfaces [18,20]. Longer-time-scale MD simulations provide an additional opportunity to quantify these relatively slow diffusional motions of interfacial by means of the Van Hove self-correlation function (VHSCF) [9],

$$
G_{S}(r, t)=\frac{1}{N}\left\langle\sum_{i=1}^{N} \delta\left[r+r_{i}(0)-r_{i}(t)\right]\right\rangle,
$$

where $r$ is the coordinate of the molecule, $t$ is time, and $N$ is the total number of molecules. This relationship describes the correlation in the positions of the same atom at different times, such that $4 \pi r^{2} G_{S}(r, t) \mathrm{d} r$ is the probability of finding an atom at distance $r$ after a time $t$ if the position of this atom was at the origin $r=0$ at the initial time $t=0$. The Fourier transform of the VHSCF represents the incoherent or self-intermediate scattering function (SISF), which can be directly measured in incoherent quasielastic neutron scattering experiments and contains detailed information concerning the single-molecule dynamics both in time and space domain.
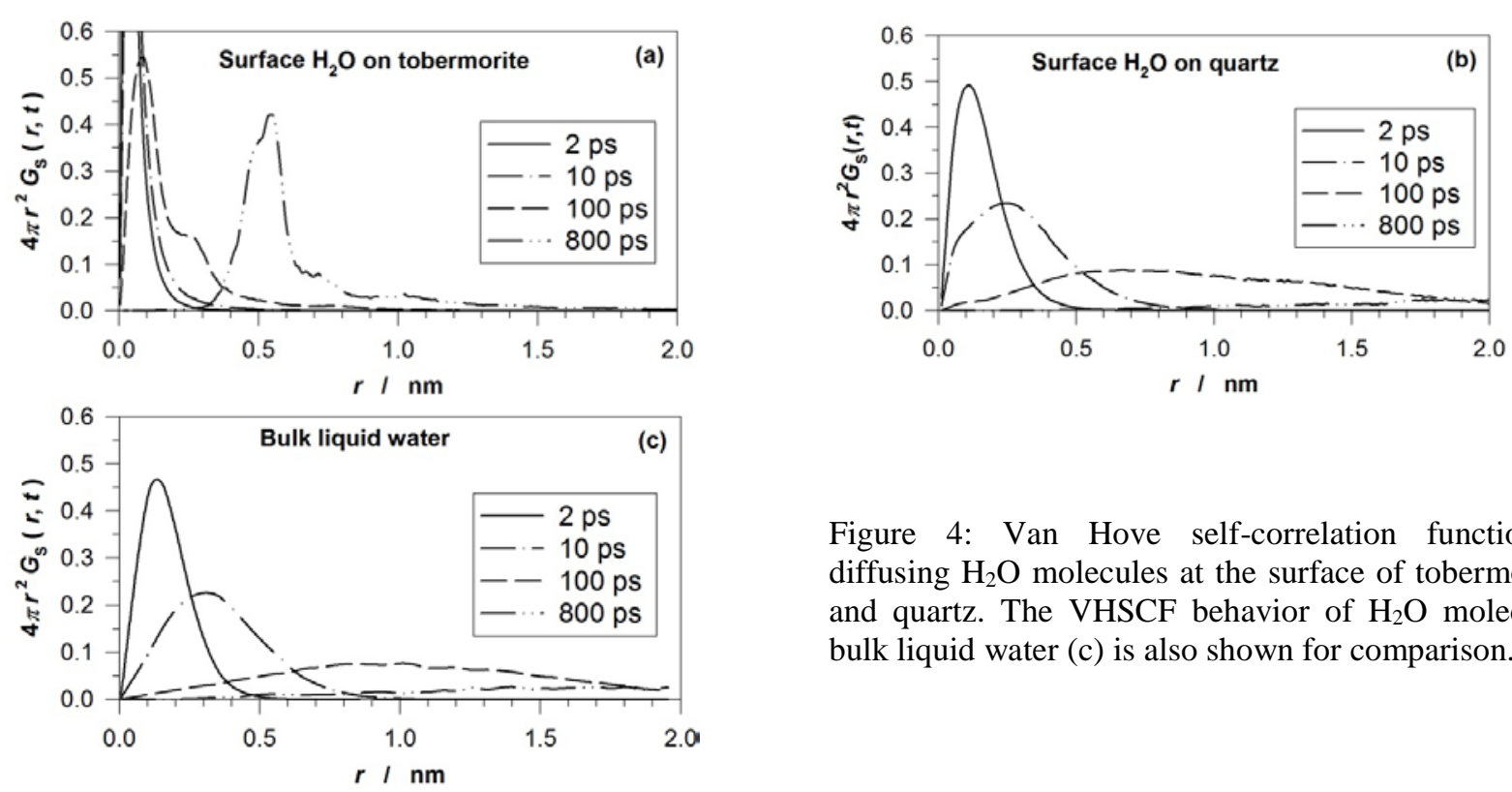

Figure 4: Van Hove self-correlation functions for diffusing $\mathrm{H}_{2} \mathrm{O}$ molecules at the surface of tobermorite (a) and quartz. The VHSCF behavior of $\mathrm{H}_{2} \mathrm{O}$ molecules in bulk liquid water (c) is also shown for comparison.

The calculation of this self-correlation function for the water molecules strongly bound to the surface of tobermorite, which exhibits nanoscale surface roughness strongly affecting the first two monolayers of $\mathrm{H}_{2} \mathrm{O}$, shows a dramatic difference in the dynamic behavior of adsorbed $\mathrm{H}_{2} \mathrm{O}$ (Fig. 4a), as compared with the diffusional dynamics in bulk liquid water (Fig. 4c), and yields a characteristic time scale of the diffusional process of the order of $\tau_{\mathrm{m}} \sim 0.8 \mathrm{~ns}$, in excellent agreement with NMR measurements, indicating a mean time between diffusional jumps on the surface of 0.8-1.0 ns [43]. The calculated long-time-scale VHSCF also points to a hopping diffusional mechanism with a length scale of $l_{\mathrm{m}} \sim 5.5 \AA$, i.e., close the characteristic lattice dimension of crystalline ice between two neighboring strong $\mathrm{H}$ bonding sites. From the two-dimensional Einstein equation, $D=\left\langle|\mathbf{r}(t)-\mathbf{r}(0)|^{2}\right\rangle / 4 \tau$, the mean time for jumps between 
surface sites from the NMR results yields a diffusion coefficient of $0.9 \times 10^{-10} \mathrm{~m}^{2} / \mathrm{s}$, which is also in remarkable agreement with the average diffusion coefficient for all surface-associated $\mathrm{H}_{2} \mathrm{O}$ molecules obtained from MD simulations $\left(1.0 \times 10^{-10} \mathrm{~m}^{2} / \mathrm{s}\right)$. Here, $\mathbf{r}$ is the mean jump displacement (assumed to be $5.5 \AA$, from the results of the VHSCF calculations, Fig.4a) and $\tau$ is the mean jump time, $\tau \sim \tau_{\mathrm{m}} \sim 0.8 \mathrm{~ns}$. This level of agreement definitely provides strong support for the interpretation of the experimental results and strong encouragement for further application of atomistic computational modeling techniques to study the molecular scale properties of nano-confined water.

The hopping surface diffusion mechanism is not evident for the water molecules at an atomically smooth surface, such as that of quartz (Fig.4b): the corresponding VHSCFs show only slight differences with the diffusional dynamics in bulk liquid water (Fig.4c).

\subsection{Effect of metal cations on the membrane fouling}

Prediction of ultrafiltration membrane performance is not generally possible without performing pilot-scale tests because membrane fouling is related to membrane material and solution chemistry. The inadequate understanding of membrane fouling has in many cases hindered wider adoption of membrane processes in large-scale drinking water treatment plants. Computational molecular modeling of the model membrane-solution interfaces allowed detailed probing of the fouling process due to the interaction of dissolved natural organic matter (NOM) with various metal cations [39]. It was observed that divalent ions $\left(\mathrm{Ca}^{2+}\right.$ and $\left.\mathrm{Mg}^{2+}\right)$ may cause membrane fouling not by forming "ionic bridges" between the negatively charged functional groups on the membrane surface and the negatively charged functional groups of NOM, but rather by promoting the aggregation of NOM molecules in solution.

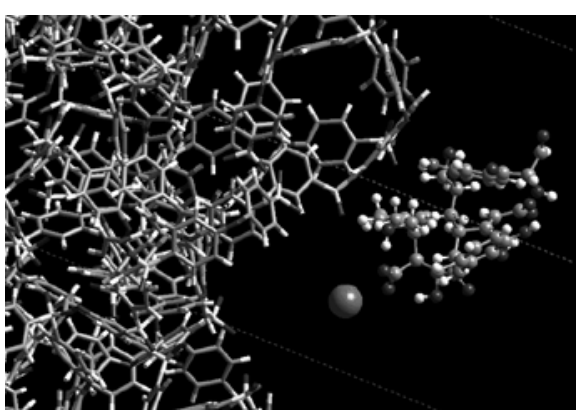

Figure 5: A fragment of the MD simulation box containing the polyethersulfone membrane surface (cylinder representation), a calcium ion (large dark ball), and a molecule of natural organic matter (ball and stick representation) coordinating to $\mathrm{Ca}^{2+}$ by its deprotonated carboxylic group. All interfacial water molecules are hidden for clarity.

Thus, even though the presence of truly dissolved NOM is not important in the fouling process, it can contribute to fouling after being aggregated by divalent ions. The partially neutralized $\mathrm{Ca}^{2+}-\mathrm{NOM}$ complex (Fig. 5) may be more easily adsorbed at the membrane surface than a negatively charged NOM molecule. However, it still remains unclear whether fouling is caused by the cation-mediated NOM aggregation in solution or by stronger NOM-surface interactions in the presence of divalent ions. Since only one NOM molecule was used in the present model, NOM aggregation could not be quantitatively studied in this work. More extensive MD simulations using multiple NOM molecules, employing much larger size of the simulated systems, and much longer simulation times (at least on the order of tens of nanoseconds) are necessary to quantitatively address these problems.

\section{CONCLUSIONS}

The methods of computational molecular modeling in application to the mineral-fluid systems have advanced dramatically in the past decade and have already emerged as very powerful quantitative tools in the studies of the structure and properties of interfacial and nano-confined aqueous solutions. There is a growing consensus, however, that the idealized mineral-fluid interfaces typically used in the present-day molecular simulations and the relatively small assemblages used in these models and in quantum calculations are at least an order of magnitude too small in characteristic length (three orders of magnitude in volume) to effectively address many critically important issues. A typical size of the systems currently simulated is on the order of a few nanometers, but can reach up to 20 nm [26] for classical force-field-based MD simulations which can probe the systems evolution over tens of nanoseconds. However, the application of quantum MD is still limited to the sizes $<1.5-2 \mathrm{~nm}$ and time periods $\sim 10$ ps. The inability to effectively model realistic compositional and structural complexity is significantly impeding further progress. For instance, idealized, defect-free mineral surfaces are of little use in predicting local charge development, which is key to understanding surface reactivity in real systems $[13,16]$. Particle edges, surface defects, the surface roughness on length scales of 10 to $100 \mathrm{~nm}$ play central roles in determining the energetics and kinetics of dissolution, precipitation, sorption and catalytic reactions at mineral interfaces, but these phenomena are currently modeled only very rarely and on a limited scale $[19,21,34,35]$. There is no doubt, however, that further rapid development of supercomputing capabilities 
will allow such molecular simulations to achieve truly realistic system sizes and time scales, thus significantly increasing their practical value.

\section{ACKNOWLEDGMENTS}

This work was supported by the US Department of Energy, Office of Basic Energy Sciences, Division of Chemical Sciences, Geosciences, and Biosciences (grant number DE-FG02-08ER-15929) and by the industrial chair "Storage and Management of Nuclear Waste” at the Ecole des Mines de Nantes, funded by ANDRA, Areva, and EDF. The supercomputing resources of the NSF TeraGrid (grant number TG-EAR000002) and of the US DOE National Energy Research Scientific Computing Center (NERSC) were used for the simulations.

\section{REFERENCES}

[1] Brown GE (2001) Surface science - How minerals react with water. Science 294:67-69

[2] Sverjensky DA (2006) Prediction of the speciation of alkaline earths adsorbed on mineral surfaces in salt solutions. Geochim Cosmochim Acta 70:2427- 2453

[3] Brown GE, Calas G (2012) Mineral-aqueous solution interfaces and their impact on the environment. Geochem Perspectives 1(4-5):483-742

[4] Fenter P, Sturchio NC (2004) Mineral-water interfacial structures revealed by synchrotron X-ray scattering. Progr Surf Sci 77:171-258

[5] Wenk H-R (ed) (2006) Neutron Scattering in Earth Sciences. Rev Mineral Geochem 63:1-471

[6] Shen YR, Ostroverkhov V (2006) Sum-frequency vibrational spectroscopy on water interfaces: Polar orientation of water molecules at interfaces. Chem Rev 106:1140-1154

[7] Cole DR, Mamontov E, Rother G (2009) Structure and dynamics of fluids in microporous and mesoporous earth and engineered materials. In: Liang L, Rinaldi R, Schober H (eds) Neutron Applications in Earth, Energy and Environmental Sciences. Springer, New York.

[8] Arbogast T (ed) (2007) Computational Needs for the Subsurface Sciences. Workshop Report. U.S. DOE Office of Science, April 2007, 291pp

[9] Frenkel D, Smit B (2002) Understanding Molecular Simulation: From Algorithms to Applications. 2nd ed, Academic Press, San Diego.

[10] Cygan RT, Kubicki JD, (eds) (2001) Molecular Modeling Theory and Applications in the Geosciences. Rev Mineral Geochem 42:1-531

[11] Kalinichev AG, Kirkpatrick RJ (2002) Molecular dynamics modeling of chloride binding to the surfaces of Ca hydroxide, hydrated Ca-aluminate and Ca-silicate phases. Chem Mater 14:3539-3549

[12] Cygan RT, Liang J-J, Kalinichev AG (2004) Molecular models of hydroxide, oxyhydroxide, and clay phases and the development of a general force field. J Phys Chem B 108:1255-1266

[13] Rustad JR, Felmy AR (2005) The influence of edge sites on the development of surface charge on goethite nanoparticles: A molecular dynamics study. Geochim Cosmochim Acta 69:1405-1411

[14] Tossell JA (2005) Theoretical study on the dimerization of $\mathrm{Si}(\mathrm{OH})_{4}$ in aqueous solution and its dependence on temperature and dielectric constant. Geochim Cosmochim Acta 69:283-291

[15] Criscenti LJ, Kubicki JD, Brantley SL (2006) Silicate glass and mineral dissolution: Calculated reaction paths and activation energies for hydrolysis of a $\mathrm{Q}^{3}$ Si by $\mathrm{H}_{3} \mathrm{O}^{+}$using ab initio methods. J Phys Chem A 110:198-206

[16] Kerisit S, Rosso KM (2006). Computer simulation of electron transfer at hematite surfaces. Geochim Cosmochim Acta 70:1888-1903

[17] Spagnoli D, Cooke DJ, Kerisit S, Parker SC (2006) Molecular dynamics simulations of the interaction between the surfaces of polar solids and aqueous solutions. J Mater Chem 16:1997-2006

[18] Wang J, Kalinichev AG, Kirkpatrick RJ (2006) Effects of substrate structure and composition on the structure, dynamics and energetics of water on mineral surfaces: MD modeling study. Geochim Cosmochim Acta 70:562-582

[19] Churakov SV (2007) Structure and dynamics of the water films confined between edges of pyrophyllite: A first principle study. Geochim Cosmochim Acta 71:1130-1144

[20] Kalinichev AG, Wang J, Kirkpatrick RJ (2007) Molecular dynamics modeling of the structure, dynamics and energetics of mineral-water interfaces: Application to cement materials. Cem Concr Res 37:337-347

[21] Larentzos JP, Greathouse JA, Cygan RT (2007) An ab initio and classical molecular dynamics investigation of the structural and vibrational properties of talc and pyrophyllite. J Phys Chem C 111:12752-12759

[22] de Leeuw NH, Cooper TG (2007) Surface simulation studies of the hydration of white rust Fe(OH) $)_{2}$, goethite $\alpha$ $\mathrm{FeO}(\mathrm{OH})$ and hematite $\alpha-\mathrm{Fe}_{2} \mathrm{O}_{3}$. Geochim Cosmochim Acta 71:1655-1673 
[23] Predota M, Cummings PT, Wesolowski DJ (2007) Electric double layer at the rutile (110) surface. 3. Inhomogeneous viscosity and diffusivity measurement by computer simulations. J Phys Chem C 111:3071-3079

[24] Allen JP, Gren W, Molinari M, Arrouvel C, Maglia F, Parker SC (2009) Atomistic modelling of adsorption and segregation at inorganic solid interfaces. Molecular Simulation 35: 584-608

[25] Cygan RT, Greathouse JA, Heinz H, Kalinichev AG (2009) Molecular models and simulations of layered materials. J Mater Chem 19:2470-2481

[26] Suter JL, Anderson RL, Greenwell HC, Coveney PV (2009) Recent advances in large-scale atomistic and coarsegrained molecular dynamics simulation of clay minerals. J Mater Chem 19:2482-2493

[27] Wang J, Kalinichev AG, Kirkpatrick RJ (2009) Asymmetric hydrogen bonding and orientational ordering of water at hydrophobic and hydrophilic surfaces: A comparison of water/vapor, water/talc, and water/mica interfaces. J Phys Chem C 113:11077-11085

[28] Argyris D, Cole DR, Striolo A (2010) Ion-specific effects under confinement: The role of interfacial water. ACS Nano 4:2035-2042

[29] Bourg IC, Sposito G (2010) Connecting the molecular scale to the continuum scale for diffusion processes in smectite-rich porous media. Env Sci Technol 44:2085-2091

[30] Malikova N, Dubois E, Marry V, Rotenberg B, Turq, P (2010) Dynamics in clays - combining neutron scattering and microscopic simulation. Zeitschrift Phys Chem 224:153-181

[31] Fenter P, Lee SS, Skelton AA, Cummings PT (2011) Direct and quantitative comparison of pixelated density profiles with high-resolution X-ray reflectivity data. J Synchrot Radiat 18:257-265

[32] Ferrage E, Sakharov BA, Michot LJ, Delville A, Bauer A, Lanson B, Grangeon S, Frapper G, Jimenez-Ruiz M, Cuello GJ (2011) Hydration properties and interlayer organization of water and ions in synthetic Na-smectite with tetrahedral layer charge. 2. Toward a precise coupling between molecular simulations and diffraction data. J Phys Chem C 115:1867-1881

[33] Rotenberg B, Patel AJ, Chandler D (2011) Molecular explanation for why talc surfaces can be both hydrophilic and hydrophobic. J Amer Chem Soc 133: 20521-20527

[34] Liu X, Lu X, Meijer EJ, Wang R, Zhou H (2012) Atomic-scale structures of interfaces between phyllosilicate edges and water. Geochim Cosmochim Acta 81:56-68

[35] Tazi S, Rotenberg B, Salanne M, Sprik M, Sulpizi M (2012) Absolute acidity of clay edge sites from ab-initio simulations. Geochim Cosmochim Acta 94:1-11

[36] Sahai N (2002) Is silica really an anomalous oxide? Surface acidity and aqueous hydrolysis revisited. Env Sci Technol 36:445-452

[37] Morrow CP, Yazaydin AO, Krishnan M, Bowers GM, Kalinichev AG, Kirkpatrick RJ (2013) Structure, energetics, and dynamics of smectite clay interlayer hydration: Molecular dynamics and metadynamics investigation of Nahectorite. J Phys Chem C 117:5172-5187

[38] Duval Y, Mielczarski JA, Pokrovsky OS, Mielczarski E, Ehrhardt JJ (2002) Evidence of the existence of three types of species at the quartz-aqueous solution interface at $\mathrm{pH}$ 0-10: XPS surface group quantification and surface complexation modeling. J Phys Chem B 106:2937-2945

[39] Ahn WY, Kalinichev AG, Clark MM (2008) Effects of background cations on the fouling of polyethersulfone membranes by natural organic matter: Experimental and molecular modeling study. J Membr Sci 309:128-140

[40] Wang JW, Kalinichev AG, Kirkpatrick RJ (2005) Structure and decompression melting of a novel, high-pressure nanoconfined 2-D ice. J Phys Chem B 109:14308-14313

[41] Wang JW, Kalinichev AG, Kirkpatrick RJ (2004) Molecular modeling of the $10 \AA$ phase at subduction zone conditions. Earth Planet Sci Lett 222:517-527

[42] Kalinichev AG (2001) Molecular simulations of liquid and supercritical water: Thermodynamics, structure, and hydrogen bonding. Rev Mineral Geochem 42:83-129

[43] Korb JP (2010) Multi-scales nuclear spin relaxation of liquids in porous media. Compt Rend Phys 11:192-203 